\title{
Interactive comment on "Decoupling of water and air temperature in winter causes warm season bias of lacustrine brGDGTs temperature estimates" by Jiantao Cao et al.
}

\section{Jiantao Cao et al.}

caojt19@tongji.edu.cn

Received and published: 13 March 2020

Response to "Interactive comment on 'Decoupling of water and air temperature in winter causes warm season bias of lacustrine brGDGTs temperature estimates'by Anonymous Referee \#1"

The authors of this manuscript examine the brGDGT distributions in the water column and surface sediments of the Lake Gonghai and its catchment. They address a critical issue for brGDGT studies which is the warm season bias of brGDGT-derived temperatures obtained in lakes. They propose a new very interesting mechanism to explain this bias implying the decoupling of air and lake water temperature during the cold season

Printer-friendly version

Discussion paper 
due to ice formation. This finding will be useful for the community and is worthy to be published. However, some improvements can be made before publication.

Response: Thanks for the comments. We have made substantial improvements according to reviewers' suggestions. Besides, some improvements were made beyond those suggestions during our revision, including title rephrasing, reanalysis sedimentary dada instead of presenting mean brGDGT values (line 1, 22-24, 216-217, 224-225, 241-242, 244-246), and reorganization of discussion (line 258-259, 382-418, 426-433, 447-471). We think the manuscript has been greatly improved in logic.

\section{Main comments}

1. The new separation method of the 5 and 6 -Me isomers should be mentioned in the introduction.

Response: We agree and have added related contents about 5 and 6-Me isomers in the introduction. Please see line 48-55 in the revision. The revised sentences are following: 'With improved analytical methods, a series of 6-methyl brGDGTs, previously co-eluted with 5-methyl brGDGTs, were identified (De Jonge et al., 2013), which may introduce scatter in the original MBT'/CBT calibration for the mean annual AT (De Jonge et al., 2014). Thus, exclusion of the 6-methyl brGDGTs from the MBT', i.e. the newly defined MBT'5ME, results in improved calibrations (De Jonge et al., 2014; Wang et a., 2016; Wang et al., 2019). Calibrations using globally distributed surface soils for the MBT/CBT, MBT'/CBT or MBT'5ME indices (Weijers et al., 2007a; Peterse et al., 2012; De Jonge et al., 2014) have been widely used for continental AT reconstruction (e.g., Weijers et al., 2007b; Niemann et al., 2012; Lu et al., 2019)'.

2. A figure with the different forms of brGDGTs could be included in appendix.

Response: Done. Figure A1 showing different forms of brGDGTs has been added in Appendix 1.

Printer-friendly version

3. Why don't you use recent regional soil calibrations for China as the one of Wang et

Discussion paper 
al., 2016 for your soil samples?

Response: Thanks for your suggestion. The regional soil calibration from Wang et al. (2016) has been applied to the Gonghai Lake, yielding $-2.42 \pm 1.19{ }^{\circ} \mathrm{C}$ from soils, $-5.86 \pm 1.30{ }^{\circ} \mathrm{C}$ from lake sediments (Table 1), $-6.20 \pm 0.60{ }^{\circ} \mathrm{C}$ in Sept (Table 1) and $-6.25 \pm 0.54{ }^{\circ} \mathrm{C}$ in Jan from SPM (Table 1). These values are significantly different from actual values, suggesting that the regional soil calibration was not suitable for soil and lake temperature reconstruction in the Gonghai Lake basin. We have added the results about brGDGT calculated temperature values from Wang et al. (2016) in the text, Table 1 and calibration in Table 2. Please see Line 279-284, Table 1 and 2 in the revision.

4. The conclusion is incomplete, you could add that soil temperature reconstructions reflect the MAAT and I think that it is important to mention that brGDGT distributions in the water column change with seasons while brGDGT productivity does not seem to significantly change. This allows you to propose an alternative explanation to warm season bias in brGDGT-derived temperature that is currently mainly considered as linked with changing brGDGT productivity.

Response: Thanks for your suggestion. The conclusion has been rewritten accordingly. Please see lines 511-529 in the revision.

5. The manuscript should be carefully checked for grammar and language issues.

Response: Done, thanks for your suggestion.

Abstract

117 mean annual

Response: Done. Please see line 17 in the revision.

Printer-friendly version

118 There are too many 'and'.

Discussion paper

Response: This sentence has been rephrased to 'we investigated the brGDGTs from 
catchment soils, suspended particulate matter (SPM) and surface sediments in the Gonghai Lake in north China to explore this question'. Please see line 19 in the revision.

I29 I think that the use of 'believe' should be avoided and the sentence should be rewritten. Suggestion: we think that lacustrine brGDGTs actually reflect the mean annual LWT (. . .).

Response: Done as you suggested. Please see line 32 in the revision.

Introduction

142 The abbreviations MBT and CBT should be defined.

Response: Done. Please see line 45-46 in the revision.

146 Some references could be added in particular, recent ones using the new separation method.

Response: Done. References 'De Jonge et al. (2014), Wang et al. (2016), Wang et al. (2019)' have been added in line 52.

153 Suggestion: brGDGTs could be produced in situ in lake environments and differ significantly from soil derived brGDGTs (. . .)

Response: Done as you suggested. Please see line 63 in the revision.

1106 'composition distribution of brGDGTs' sounds odd to me, I suggest you to change it in the entire manuscript and replace it by 'brGDGT distribution'.

Response: Done. Please see line 63, 69, 116-117, 254, 260, 511, 514, 796 in the revision.

Printer-friendly version

1107 and further discuss . . .

Discussion paper

Response: Done. Please see line 118 in the revision. 
Materials and methods

1112 Mention 'N' and 'E' for latitude and longitude.

Response: Done. Please see line 123 in the revision.

I119 concentrated

Response: Changed. Please see line 130 in the revision.

I146 combination of

Response: Changed. Please see line 161 in the revision.

I146 and 150 'DCM' and 'MeOH' could be used for dichloromethane and methanol defining the acronym at the first appearance.

Response: Done. Please see line 160 and 165 in the revision.

I157 Mention what are 'A' and 'B'.

Response: Done. Please see line 172 in the revision.

I167 Remove the ';' after(2)

Response: Done. Please see line 183 in the revision.

I169 The authors could mention Martin et al., 2019 who modified the initial definition of the IIla/lla ratio proposed by Xiao et al., 2016.

Response: Done. Please see line 184-185 in the revision.

$1170 \mathrm{~A}$ word is missing as well as a punctuation mark.

Response: Done. Please see line 186 in the revision.

1177 Add a figure in appendix describing the different brGDGT structures and refer to it here. 
Response: Done. We have added the figure about brGDGT structures in Appendix 1.

Results

I206 typical for in situ produced lacustrine (. . .)

Response: Done. Please see line 221 in the revision.

\section{Discussion}

I221 This title is not very clear, maybe 'Different sources of brGDGTs in the Gonghai Lake' or 'In situ production of brGDGTs in the Gonghai Lake'.

Response: Thanks for your suggestion. We have changed 'Different sources of lacustrine brGDGTs from surrounding soils' to 'In situ production of brGDGTs in the Gonghai Lake'. Please see line 249 in the revision.

1226 and/or surface sediments. I would not mention brGDGT concentrations as a discriminant factor between soils and in situ production, differences of concentrations, alone, would not be a proof of the occurrence of in situ production as several other parameters could be involved.

Response: We found content of brGDGTs in surface sediments is significantly higher than that in surface soils (Table 1), and increases with water depth (Table 1). Therefore, we think it suggests a possible autochthonous contribution in Gonghai Lake. We have added 'Moreover, they exhibited a clearly increasing trend with water depth' in the revision, please see line 258-259.

I227 comparison of brGDGT distribution

Response: Changed. Please see line 260 in the revision.

I232 was similar to that of SPM ... from that of soils

Response: Changed. Please see line 260-261 in the revision.

Printer-friendly version

I236 The $\Sigma$ IIla/ $\Sigma$ Ila values in sediments and SPM were

Discussion paper 
Response: Changed. Please see line 266 in the revision.

I238 the $\Sigma \mathrm{IIla} / \Sigma$ Ila ratio in sediments and SPM was significantly higher than in catchment soils.

Response: Changed. Please see line 266 in the revision.

1239 sediments are

Response: Changed. Please see line 269 in the revision.

I243 It does not appear very clearly that \#Ringstetra were higher in sediments than in soils, a statistical test would be appreciated.

Response: Thanks for your suggestion. We have added t-test in the revised sentence, please see '... \#Ringstetra and \#Ringspenta 5ME were clearly higher in sediments than in catchment soils ( $p<0.05$ for \#Ringstetra, $p<0.01$ for \#Ringspenta $5 \mathrm{ME}$ ), although \#Ringspenta $6 \mathrm{ME}$ in sediments was similar to that in catchment soils $(p=0.11$ for \#Ringspenta 6ME; Fig. 3b)' in line 273-275.

I257-258 in globally distributed lakes?

Response: We have changed 'in global lakes' to 'in many modern lake sediments'. Please see line 288 in the revision.

I270 You should provide the reader with the analytical error associated with the MBT indices in the method section for a better evaluation of the changes discussed here.

Response: We have added the analytical error in the method. Please see 'Based on duplicate HPLC/MS analyses, the analytical errors of both the MBT'5ME and MBT'6ME index were \pm 0.01 units' in line 177-188 in the revision.

I274 You should add a reference to Fig. 2. You should at least mention that the deepest SPM shows an opposite trend which seems to indicate that at this depth, temperature is not the only parameter controlling brGDGT distributions.

Printer-friendly version

Discussion paper 
Response: In revised Fig. 2, the MBT'5ME and MBT'6ME index trace the water temperature changes at different depth in Sept and in Jan, and it seems that MBT'5ME and MBT'6ME index could response to water temperature changes to some extent. However, the seasonal changes of SPM brGDGT derived temperature between Sept and Jan were small, which could be influenced by the several reasons in addition to water temperature, such as residence of "fossil" brGDGTs and sediment resuspension, as evidence of smaller differences in MBT'5ME and MBT'6ME between sediments and SPM at deeper sites. We have discussed the detailed reason about it in the later paragraph. Please see line 391-409 in the revision.

I275 seasonal temperature changes?

Response: This paragraph have been rephrased. Please see line 383-390 in the revision.

I276 previously Response: This paragraph have been rephrased. Please see line 383390 in the revision.

1276-277 The phrasing sounds odd to me. Suggestion: suggest that both . . . could respond to temperature changes.

Response: This paragraph have been rephrased. Please see line 383-390 in the revision.

1278-279 African ; the phrasing is not very clear here.

Response: This paragraph have been rephrased. Please see line 383-390 in the revision.

I283 I suppose that 0.3 corresponds to the difference of the mean temperatures obtained for September and July? You could specify it.

Response: We have revised sentence as 'Although the MBT'5ME and MBT'6ME in SPM in the lake seem to reflect temperature changes in the water column to some

Printer-friendly version

Discussion paper 
extent, the differences of brGDGT-derived temperatures based on lake-specific calibrations between September and January $\left(-0.93-1.21^{\circ} \mathrm{C}\right)$ are much lower than the measured difference $\left(\sim 13^{\circ} \mathrm{C}\right)$, independent of the calibration of (15), (16) or (17) (Tables 1 and 2)'. This could be clear for reader. Please see line 391-394 in the revision.

1284 remove the '. after (16).

Response: Done. Please see line 394 in the revision.

I286 multi-seasonal

Response: Changed. Please see line 401 in the revision.

1287 previously

Response: This paragraph have been rephrased. Please see line 391-409 in the revision.

I292 could also be

Response: This paragraph have been rephrased. Please see line 391-409 in the revision.

I293 the shallow water depth of the lake

Response: This paragraph have been rephrased. Please see line 391-409 in the revision.

1293-294 The sentence is not very clear and too long, you should maybe cut it into two sentences.

Response: This paragraph have been rephrased. Please see line 391-409 in the revision.

Printer-friendly version

1296-299 Terrestrial inputs are almost not discussed, could they have a role in seasonal changes of brGDGTs?

Discussion paper 
Response: Just as discussed in the text, several parameters, such as $\Sigma$ Illa/ $/ \mathrm{lla}$, IR6ME, \#Ringstetra and \#Ringspenta in SPM were in-between the soil and sediment values, we speculate terrestrial inputs may be a factor, if any, to reduce the seasonal changes of brGDGTs in SPM. Please see line 407-409 in the revision.

I297 Be coherent with the notation of $\Sigma$ IIla/ $/ \Sigma$ Ila.

Response: Done. Please see line 407 in the revision.

1300-304 You should mention here or in the previous paragraphs that SPM samples also reflect temperatures close to warm season AT.

Response: Done. Sedimentary brGDGTs in Gonghai Lake reflected temperature close to warm season AT. Due to sediment resuspension, the warm season bias also occurred in SPM. We have discussed it in line 428-433 in the revision.

I302 You could add a reference to the table 1 . Is it 13.2 or 13.5 ?

Response: Done. The number of 13.5 is correct according to the results in Table 1.

I305 correlated significantly

Response: Done. This paragraph have been rephrased and this word has been deleted.

I314 are thought to . . .

Response: Done. This sentence has been rephrased. Please line 356-358 in the revision.

I314-325 You say in situ production is thought to be the main source of brGDGTs in many lakes so why do you only consider six lakes in fig 5 ? What about the others?

Printer-friendly version

Response: We selected these five lakes for several reasons. (i) The brGDGTs-related data from both the lake surface sediments and the catchment surface soils were available. (ii) The lakes are in different regions, and together with Gonghai Lake in this 
study, they span a relatively large environmental gradient. (iii) The authors of these studied lakes have claimed that brGDGT distribution in lake sediments differed from catchment soils as we do in Gonghai Lake in this study. As to others lakes, due to the lack of catchment soil brGDGT data, they are not shown in revised Figure 5, although brGDGT-derived temperatures are also warm season biased. We have added related content in the revised manuscript. Please see line 358-381 in the revision.

1319-325 Rephrase

Response: Done. Please see line 371-381 in the revision.

I332 You should also mention that brGDGT distribution in water column seems to change seasonally in agreement with temperature, what you discussed in the $4.3 \mathrm{sec}$ tion.

Response: Although the MBT'5ME and MBT'6ME in water SPM mirror the water temperature change in Sept and Jan, the calculated seasonal temperature offsets was quite small in Gonghai Lake. So we don't emphasize this phenomenon. We have added related content in the revised manuscript. Please see line 391-409 in the revision.

I339 Rephrase

Response: Done. Please see line 441-444 in the revision.

I350 Most of stratified lakes . . .

Response: Done. This paragraph has been rephrased and this word has been deleted.

I365 Can you add a reference?

Response: Done. Please see line 474 in the revision.

Printer-friendly version

I378 universal

Discussion paper

Response: Changed. Please see line 487 in the revision. 
I383 compatible with the mechanism that we propose here

Response: Changed. Please see line 492 in the revision.

I391 Use cold season rather than 'winter'.

Response: This paragraph has been deleted.

Conclusion

1403 from that in soils

Response: Changed. Please see line 515 in the revision.

1403-404 indicating that lacustrine brGDGTs are mainly produced in situ . . .

Response: Changed. Please see line 515 in the revision.

1404 in surface sediments of Lake Gonghai

Response: Changed. Please see line 521 in the revision.

1406 water-air decoupling in Lake Gonghai

Response: We don't add “in Lake Gonghai” here because we think the sentence is ok.

Figure 1

(a) northern limit ? (b) For the latitude replace 'E' by N 1655 represent

Response: Changed. Please see in the revised Figure 1.

Figure 3

fractional abundance Maybe specify: water column (SPM).

Response: Changed. Please see line 796 in the revision.

I667 Use degree of cyclisation rather than 'cyclisation ratio'.

Response: Done. Please see line 797-798 in the revision. 
Figure 4

1670 soil calibration.

Response: This figure have been replace, please see revised caption Figure 4.

Figure 5

1679 A comma missing before Lake Donghu.

Response: Changed. Please see line 811 in the revision.

1676 Mention the number of the equation used.

Response: Done. Please see line 807-810 in the revision.

Table 1

1695 For b et c, mention the number of the equation used.

Response: Done. Please see the note of Table 1 in the revision.

Table 3

1705-708 Mention the number of the equation used.

Response: Done. Please see the note of Table 3 in the revision.

Please also note the supplement to this comment:

https://www.biogeosciences-discuss.net/bg-2019-507/bg-2019-507-AC1-

supplement.pdf

Interactive comment on Biogeosciences Discuss., https://doi.org/10.5194/bg-2019-507, 2020.

Printer-friendly version

Discussion paper 


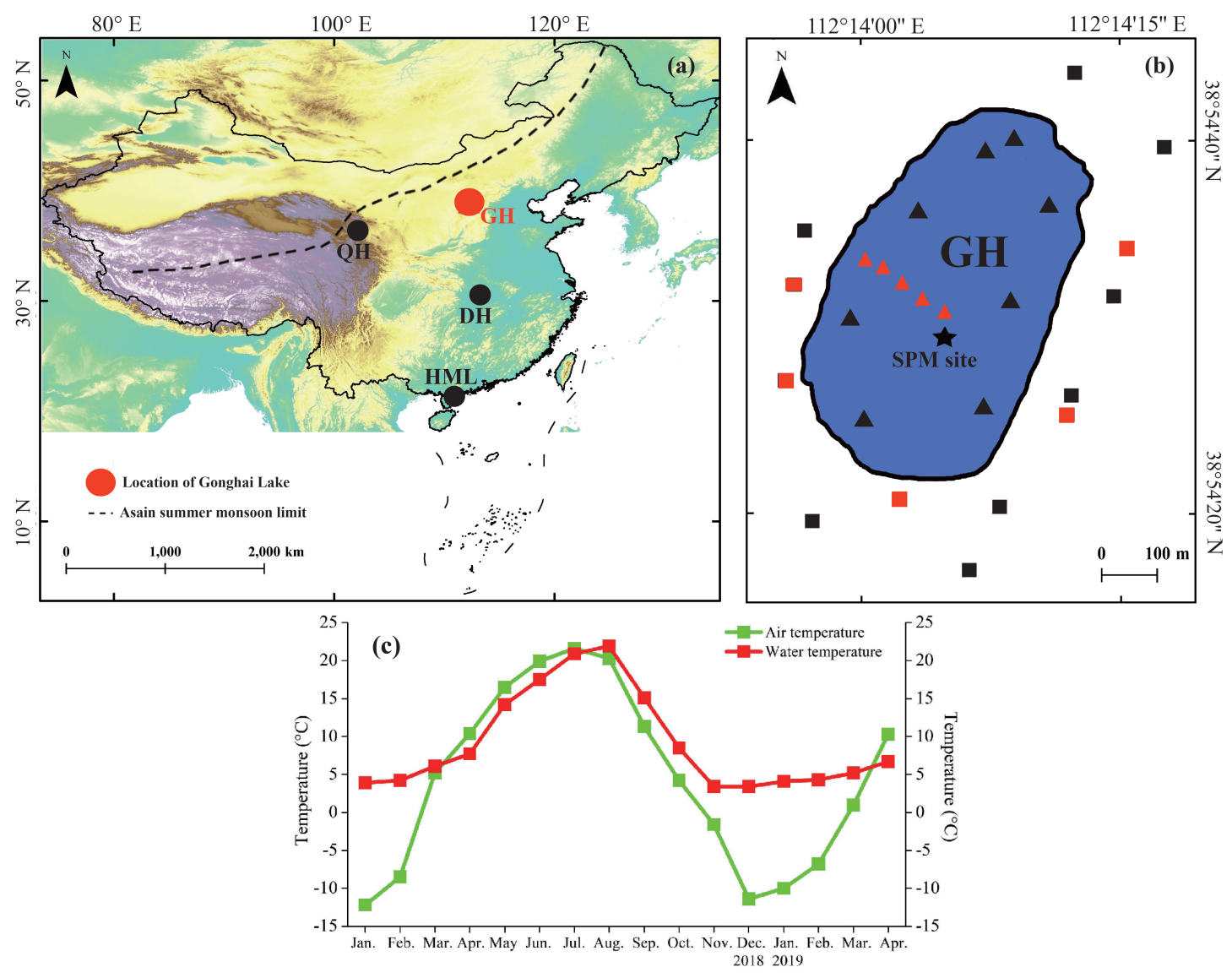

BGD

Interactive

comment

Printer-friendly version

Discussion paper

Fig. 1.

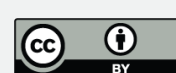



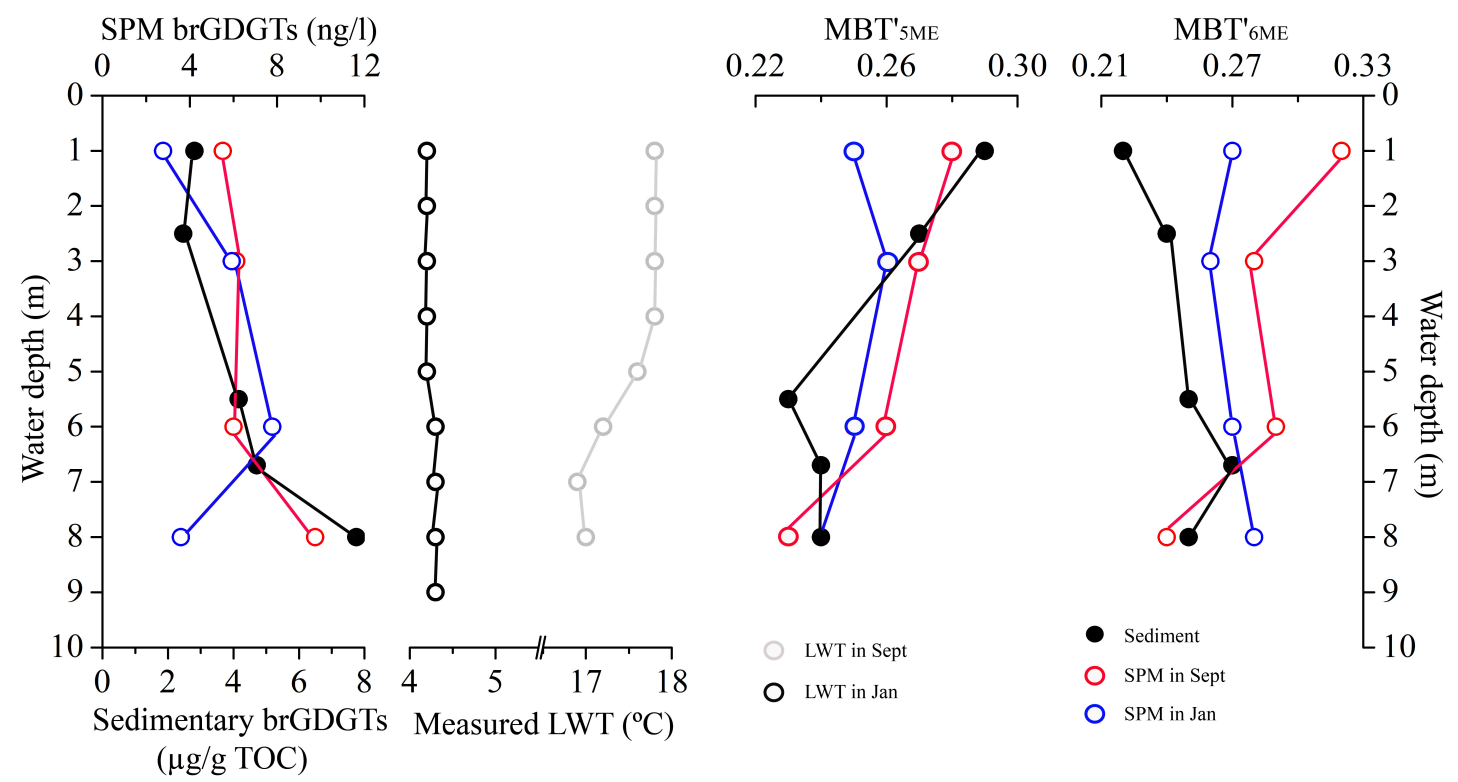

Interactive

comment

Fig. 2. 


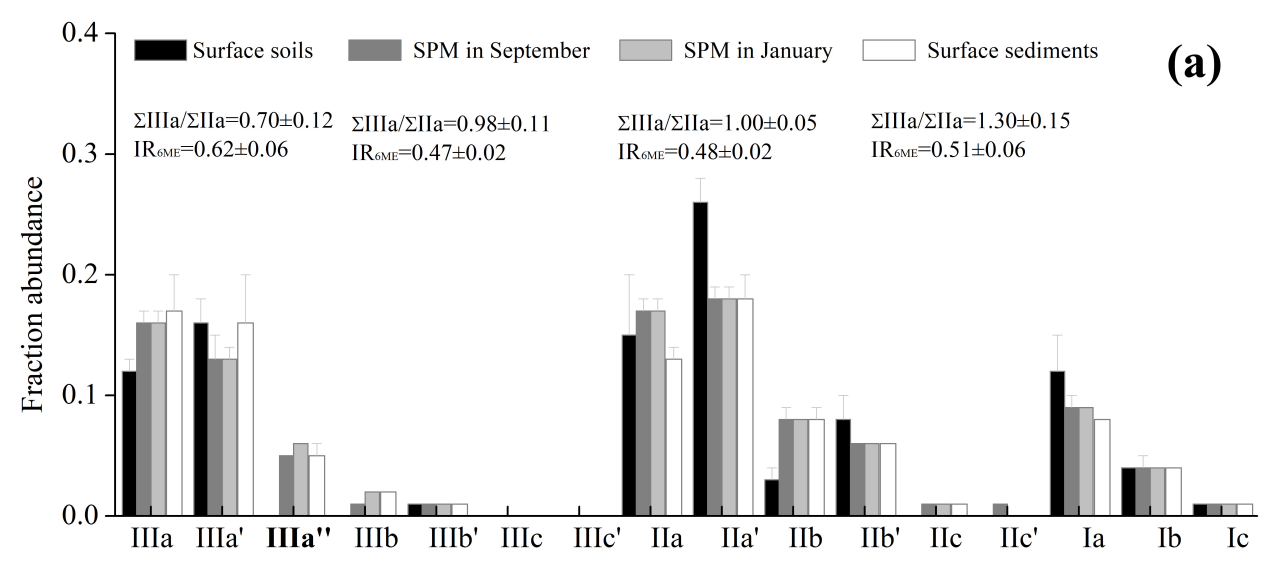

BGD

\section{Interactive \\ comment}

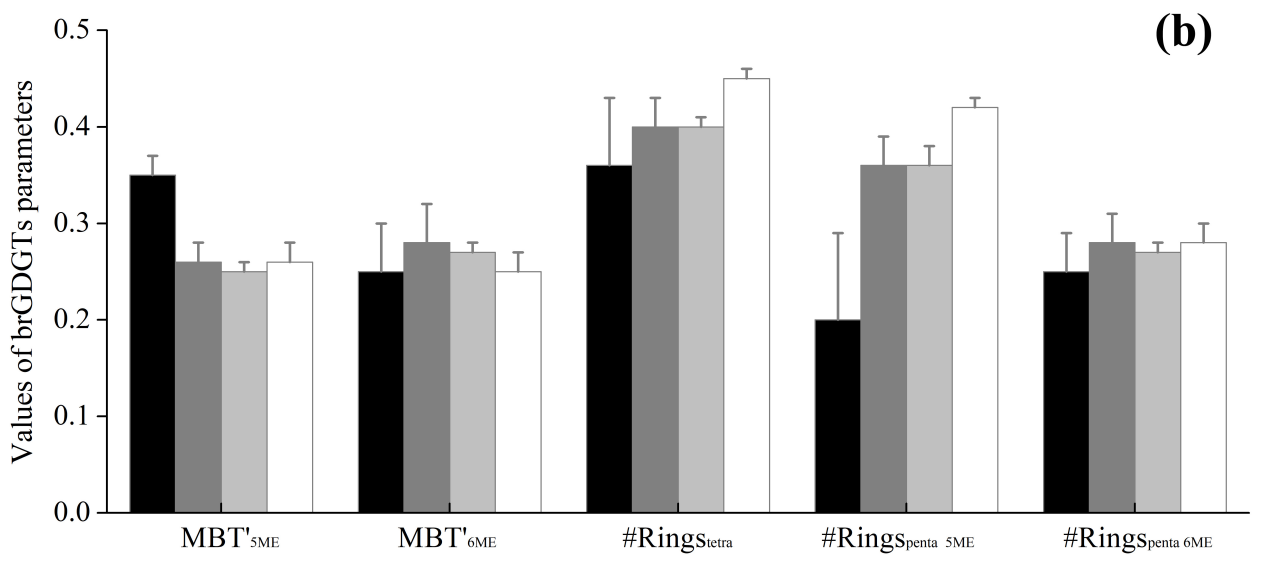

Printer-friendly version

Fig. 3.

Discussion paper 


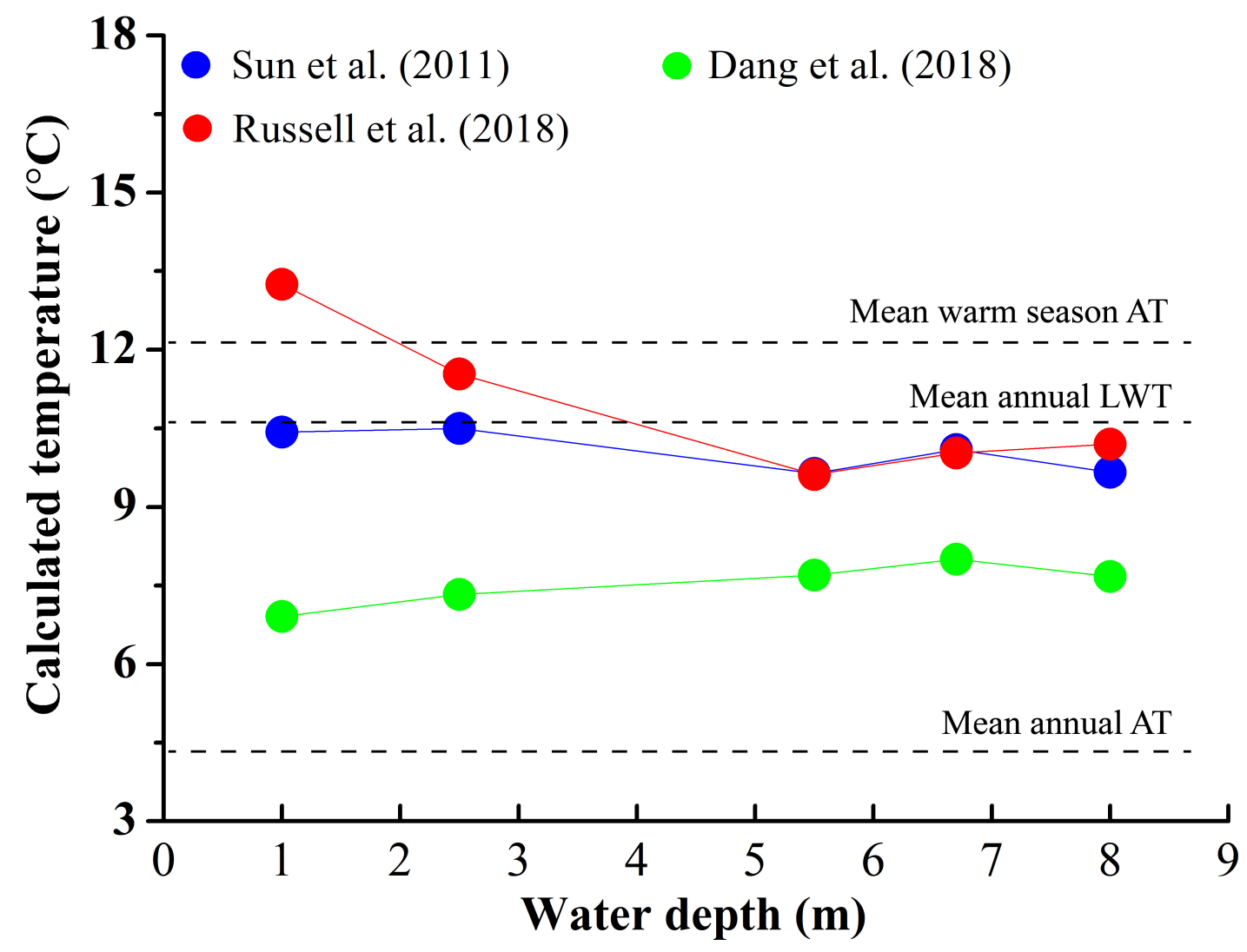

Interactive

comment

Fig. 4. 
Interactive

comment
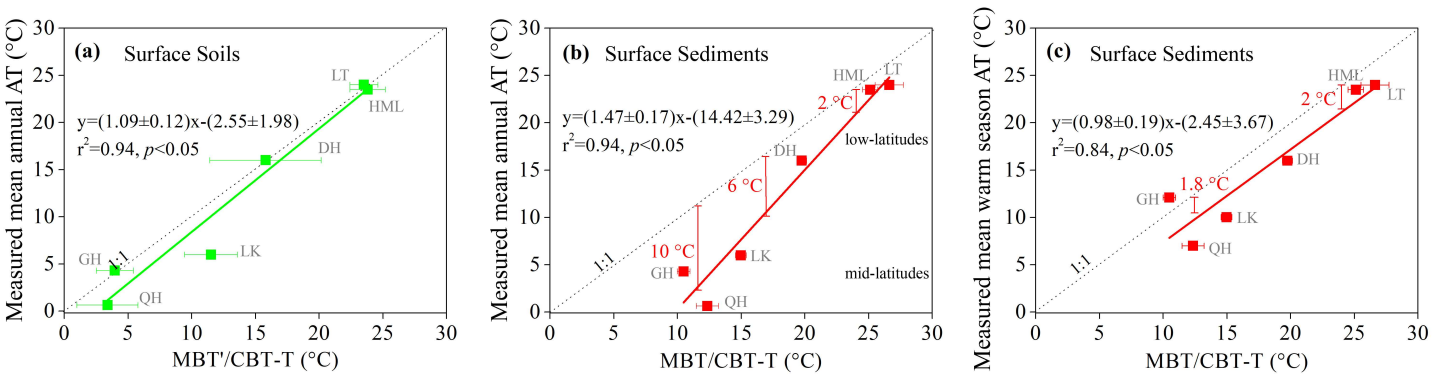

Fig. 5. 